Understanding Customer Value in Technology-Enabled Services: A Numerical Taxonomy Based on Usage and Utility

Min Kyung Lee, Rohit Verma, and Aleda Roth

May 21, 2015

Min Kyung Lee

College of Business and Behavioral Science

Clemson University

Clemson, SC 29634,

minl@g.clemson.edu

Rohit Verma

School of Hotel Administration

Cornell University

Ithaca, NY 14853

rv54@cornell.edu

\author{
Aleda Roth \\ College of Business and Behavioral Science \\ Clemson University \\ Clemson, SC 29634 \\ aroth@clemson.edu
}




\title{
Understanding Customer Value in Technology-Enabled Services: A Numerical Taxonomy Based on Usage and Utility
}

\begin{abstract}
Use of technologies in service encounters can enhance service delivery and increase customer satisfaction in services. Our research develops a numerical taxonomy that provides a deeper understanding of usage and value of customer-facing technology-based innovations in the U.S. restaurant industry. In this study, utility is a proxy for intrinsic customer value. Usage was estimated by past visits to restaurants and utility was calculated by using a specific type of discrete choice experiment known as Best-Worst (or max-diff) experiment. We offer insights for service strategy technology choices and customer value in service delivery systems research and practice. Furthermore, we advance service science by discussing the inherent management pitfalls of failing to distinguish between technology usage and utility in services.
\end{abstract}

Keywords: technology-based innovations; best-worst experiment; cluster analysis; numerical taxonomy; restaurant industry 


\section{Introduction}

“There is no such thing as a service industry. There are only industries whose service components are greater or less than those of other industries. Everybody is in service.” Levitt (1972)

It is the customer who determines what a business is. It is the customer alone whose willingness to pay for a good or for a service converts economic resources into wealth, things into goods. And what the customer buys and considers value is never a product. It is always utility, that is what a product or service does for him. Drucker (1974)

This paper aims to provide a richer understanding of customer value in technologyenabled services by developing two numerical taxonomies based on two dimensions of technology: (1) usage and (2) customer utility (hereafter, utility). Numerical taxonomies are useful in establishing strategic groups that have common profiles on some defining characteristics (see, for example, Miller and Roth 1994, Verma and Young 2000). Industry reports from various trade organizations demonstrate that many services, such as restaurants and hotels, are increasing spending on technology-related initiatives at a very fast rate. For example, the restaurant industry in the United States spent on average 5.8 percent of its revenue on technology in 2014 (compared to 3.5 percent in 2013) (Lorden and Pant 2015). In the same study, the restaurant executives state that "business efficiency” and "customer engagement” were the two most important reasons for investing in technology-based innovations, measured at 66 and 53 percent, respectively (Lorden and Pant 2015). Although usage is a function of customer choice based on the options offered in the service delivery system, utility is a measure of intrinsic customer value for options that may or may not have been offered in the service encounter or the marketplace. In other words, utility captures the technology choices they would 
prefer, if the option were available to them in the service system. Specifically, we ask the following questions: In services, can we identify configurations of customers groups that view the usage and utility of technology in the same ways? Can we develop strategic groups of customer segments, whose profiles are based upon the technology utility attributes that create value for them? What factors contribute to customer utility and what are the potential pitfalls?

Peter Drucker (Drucker 1974) and several other management scholars (e.g., Woodruff 1997, Zeithaml 1988) have repeatedly emphasized the importance of customer value as a guiding framework when evaluating a product (e.g., good, service, or a good-service bundle) innovation. Roth et al. (1995) report that most service designs are based on internally-oriented processes (e.g., "increasing desired levels of automation to achieve the desired levels of internal efficiency and effectiveness" [p. 454]), but few prioritize technologies and processes most "valued" by customers. In other words, in service operations, many companies may favor lowering costs over increasing revenues by creating better customer experience with technologies that are valued by customers (Voss et al. 2008). Furthermore, customer value is inherently related to customer choices; therefore, the utility of products and services matters (Drucker 1974). The authors collectively call for creating a new class of competitiveness that maximizes value-added to customer, and in turn, point to significantly new business models for services. Xue et al. (2007, p. 536) elaborate on the potential duality of value to service firms and customers:

The appeal of adding customer self-service to the overall service delivery mix is straightforward. By offloading task onto customers and enabling them to pursue their own service needs, firms can often provide customized services at mass production cost levels. In addition, many of the technologies underlying self-service such as 
Internet-based ordering or customer support also enjoy significant economies of scale while providing greater access, flexibility and convenience.

However, the concept of customer value has become an important management tool and has been adopted extensively in the fields of marketing and management, but its role in service operations strategy research is relatively sparse, especially as it pertains to the customer perspectives of technology-based value creation in services versus usage. Take an example of self-service technology usage. The former US Airways mandated customers use self-service technology during the airport check in process, even if they printed their boarding pass from an online source. Notably, the automated check-in machine usage was very high and for some customers, perceived value was created. However, other customer groups perceive negative value-added. For instance, those that had already made the effort to print out their boarding pass felt inconvenienced by the mandate, whereas others didn’t value self-service over regular employee check-in processes. Not understanding the distinction between usage and value in the customer contact process design can redirect scarce technology investments to the wrong place, and in turn, create a disconnect. This research aims to fill this gap, in part, by empirically addressing the distinction between the usage of technologies and those that customers actually value in the context of restaurant services.

Although customer value can be defined in many different ways depending on the context and the perspectives of researchers, some commonalities exist among diverse definitions (e.g., Woodruff 1997). For example, customer value might be perceived from perspective of usage of products or service offerings. Customer value can also refer to customers' perception of benefits or utilities gained in exchange for the costs incurred in using a product or experiencing service (e.g., Woodruff 1997, Parasuraman 1997, Paananen and Seppanen 2013). However, 
according to Paananen and Seppanen (2013), the heart of customer value centers around "understanding and capturing customer expectations, creating and delivering desired customer experiences, and assessing and managing the customer evaluation” (p. 723).

There is also a general agreement among scholars that customer value is intrinsically related to the benefit or utility provided by the purchased product. Simplistically stated, we can assume that a customer's choice of a product is influenced by her desire to maximize her preferences or utility. Louviere (1988), Nobel Laureate McFadden (1986), and other scholars (e.g., Verma et al. 1999) describe utility as the overall evaluation of a product by customers, taking into account all its determinant attributes and their relative weights. The customer utility framework described above can be very useful in identifying the value of each component (e.g., quality, features) of a product offered in the marketplace. For example, if a product with a specific combination of attributes is highly successful in the marketplace, then the utility framework suggests that the customer value for these specific product attributes is high. Conversely, the utility framework also suggests that a product, which is not chosen by customers, must include attributes that customers do not find valuable.

Furthermore, as Levitt (1972) eloquently pointed out, most products purchased in the marketplace by customers include both tangible goods and intangible services. Although the utility framework can be applied with relative ease to quantify customer value for tangible components of a product, the framework's application for quantifying the value of intangible service components is more complex. Furthermore, since increasingly more services are being delivered via a combination of face-to-face and technology-enabled systems, the quantification of customer value becomes even more challenging. Technology-enabled services can provide benefits both to customers and providers if their customers find them to be valuable. Therefore, 
without understanding the customer value for technologies that are embedded in the service delivery, a firm's offering may not be successful in the marketplace (Froehle 2006, Froehle and Roth 2004, Ding et al. 2007, Iqbal et al. 2003). For example, many firms have started offering services that are delivered with the assistance of smart phones, tablets, and touch-screen computers. Examples of technology-enabled services are also present in diverse range of industries that include healthcare, travel and hospitality, restaurants, and retail, among others (e.g., West 2012).

Although the benefits of technology-enabled innovations in service organizations may be obvious, we argue that understanding customers' usage and utility of new technologies is critical. Without the systematic understanding of both usage and utility of specific technology-based innovation, a firm may misinterpret the value of a specific technology, resulting in negative outcomes and customer backlash (Bitner et al. 2000). Therefore, when service operators decide which types of technologies they should adopt to increase customer satisfaction and employee efficiency, they must consider not only the costs and benefits of that technology but also customers' reactions to the changes accompanying the new technology (Walker et al. 2002). Thus, it is very important for service providers to determine a way to prioritize customers' preferences to maximize the value for customers (Victorino et al. 2005).

This study presents a comprehensive analysis of customer usage and utility for technology-based innovations in the U.S. restaurant industry. We assert that the next generation of customer value creation in service operations strategy through technology necessitates a keen awareness of what customers value at each facet in the delivery process. We introduce numerical taxonomies of customers with specific attribute variables forming the basis (more formally, taxons) for the classification scheme. Taxonomies provide parsimonious group descriptions that 
can potentially improve operations management and strategy designs (Miller and Roth 1994, Verma and Young 2000). We also examine how the customer groups systematically differ from one another in terms of other important variables that are not used to define the clusters in the first place. These additional variables provide insights into the characteristics of the strategy groups that are relative to technology usage and utility. We estimate the customer utility for technology-based innovations using a special type of discrete choice experiment known as the “Best-Worst” experiment (Finn and Louviere 1992). Although the benefits of using technologies have been acknowledged in the field of marketing and information systems, little is known about customers’ perspectives of the technology in terms of its utility and value. We argue that segmenting service customers based on their usage and utility-based preferences will inform industry and researchers as a novel way to explain differences in customer segments-a way that can potentially create strategic value for company and raise new empirical research and theory building for researchers. Also, discovering the key attributes valued inherently by different customer groups will help industry to develop particular products or services that reflect customer values dynamically. Particular technologies mature and new ones are introduced over time. If a firm does not understand the difference between these two related yet different constructs — usage versus utility—it may continue to invest only in technologies based on past usage; and consequently, miss out on opportunities that could potentially be more beneficial in ultimately leading to higher customer satisfaction, loyalty, and share of wallet. Past academic research shows that when service technologies are advancing at a fast pace, customers may face a number of different choices on how they may choose to interface with service providers (Huete and Roth 1988). Therefore, underlying attributes of service technologies in terms of customer value likely evolve along with any fundamental shifts in the physical and virtual characteristics 
of the technology available to them (Froehle and Roth 2004). Thus, the first purpose of this paper is to empirically derive numerical taxonomies of strategic groups of customers who share common patterns in their usage and utility of customer interface and enabling technologies in stages of service delivery. Second, deepening our understanding the underlying characteristics of these strategic customer groups (hereafter, strategic groups) offers a rich platform for designing and delivering technology-based service innovations for the specific customer segments as they adjust their preferences to particular technology attributes over time. Third, our strategic groups offer a springboard for advancing service science-based operations strategy research and practice on sources of customer value creation with technology.

The structure of the article is organized in the following manner: First, we give a general overview of the previous research regarding the customer value and technology innovations in the service industry. Next, we discuss the customers’ technology usage and utility; we then describe our research methods and the application of our study. Then the results are presented, followed by a discussion of the theoretical and managerial implications of the study. We conclude with the limitations and future research directions for customer-facing, technologybased innovations that consider both benefits of customers and service operations.

\section{Background}

In this section of the paper, we review past research related to technology-based innovations and customer value. We also discuss the concept of customer value in our study and how customer value is parlayed in the service sector. 


\subsection{Customer Value in Service Operations}

Customer value within the marketing discipline reinforces customers and the relationship with customers since customers are important assets for firms (Estrella-Ramon et al. 2013). The relationship with customers is a critical resource for competitive advantage for the firm because the longer customers stay with the firm, the higher profits the firm utilizes. To identify the most profitable customers to the firm, a metric such as customer lifetime value or customer relationship management has been developed to evaluate marketing decisions (Gupta et al. 2006, Estrella-Ramon et al. 2013, Borle et al. 2008). From a marketing perspective, customer value revolves around a link between organization and customers. Continuous interaction between these two parties will provide organizations with useful information about customers' behavior and help organizations satisfy customers, which ultimately impacts business performance (Morgan and Hunt 1994).

Customer satisfaction has been an important measure for organizations to assess their performance. However, this metric has been ignored by many decision makers because of its limitations of not reflecting prospective customers’ perspective (Swaddling and Miller 2002). Customer satisfaction measurement is limited to only the customers' past experience, asking them how they felt about the particular products or offerings and without including potential customers. To overcome this issue, researchers have started to shed light on customer perceived value in service delivery systems as an alternative metric to better reflect customer values and needs (Swaddling and Miller 2002, Roth et al. 1995). By thoroughly assessing customer wants and needs, customer perceived value aids researchers in identifying targeted markets and predicting customer behavior more effectively. Organizations want to understand the customer's perspective of value, to identify what is important to them and what customers value in using the 
service or products that organizations offer. Zeithaml (1988) defines customer value as consumers' overall assessment of the utility of a product based on the perception of what is achieved in terms of their own personal values. To increase customers' overall assessment of the product, organizations should be aware of whether components of the service product bundle delivers value for customers (Verma and Plaschka 2003, Roth and Menor 2003). Because organizations frequently develop new products and service offerings, customers may be exposed to too many choices. In spite of organizations' investment and efforts in developing new products for their customers, some of the new products and service offerings seem to have relatively low perceived value or preferences from their customers (Verma and Plaschka 2003). Marketing often promotes many products and services without carefully considering how customers would react or perceive each of them. For example, HTC First, also known as the Facebook phone, failed in less than a month after its introduction. Very few people wanted to have Facebook at the heart of their phones (Worstall 2013). HTC failed to understand what customers value with their smart phone.

Thus, understanding the real customer value associated with a particular product or service bundle offered is imperative. Verma and Plaschka (2003) develop the framework that supports organization's sustainable benefits by discussing its ambiguity, risk, and conformity in a market. According to Verma and Plaschka (2003), for organizations to survive in a competitive environment, they should possess a capability of interpreting customers' needs in a precise way and should be able to modify their current products or service offerings accordingly based on what customers deem important. Also, effective operations that balance out organizations' capability and customers' needs should be followed to fully understand market-value drivers. 
Davidow and Uttal (1989) discuss the importance of organization's strategy to understand who their customers are and what their needs are, so organizations can minimize the conflicts between the corporate strategy and the customer's perceived service value. They also suggest that for organizations to better position their products and service offerings, organizations should invest their efforts and money into developing different strategies depending on different customer segments (Davidow and Uttal 1989). Likewise, Heskett (1987) asserts that the value of the service to customers can be maximized through the link between the service concept and the operating strategies. According to Heskett (1987), the identification of target market segments should come first in developing a service concept and operations strategy. Holcomb (1994) also identifies customer service delivery attributes and segments customer groups using factor and cluster analysis to examine which variables have a large or small influence on the mean value of service performance. From the service operations strategy perspective, organizations must focus on determining the types of product and service attributes that constitute the service bundle that will motivate customers' purchase decisions and increase their value (Roth and Menor 2003). However, it is challenging and debatable to measure the customer value because it is evaluated based on individuals' experiences with products and intrinsic preferences or utility (Ervasti 2013). It is valuable for organizations to incorporate customers' utility regarding product and service attributes into the design of service delivery processes (Verma et al. 2002). Many past studies describe that discrete choice experiments and its variant Best-Worst experiments (also known as maximum difference or "max-diff” scaling) are effective ways to determine customer utility and assess the trade-offs with respect to the various product and service attributes (Louviere and Woodworth 1983, Verma et al. 1999, Finn and Louviere 1992). These approaches provide a robust and systematic way to evaluate the 
relative weights and attribute trade-offs experienced by customers. These methodologies will be detailed in research design $§ 3.2$.

In our study, we are interested in examining how customers perceive the different types of technologies based on the attributes offered by various service technologies. Thus, we take Woodruff's definition of customer value: “A customer’s perceived preferences for an evaluation of those product attributes, attribute performances, and consequences arising from use that facilitate achieving the customer’s goals and purposes in use situations” (Woodruff 1997, p. 142). Our numerical taxonomy allows us to define strategic groups of customers based on their usage and utilities for various types of technology attributes, which can be useful in linking service technologies to various market segments.

\subsection{Utility as Intrinsic Customer Value in Technologies}

Utility theory is derived from an economic concept measuring people’s preferences or values over a good or service in numerically useful ways (Fishburn 1968). Utility theory is associated with people's choices and decisions and makes it possible to rank the alternatives in their order of preferences (Stigler 1950). Utility theory is often incorporated with decisionmaking process under uncertainty. Organizations choose the strategy that maximizes the expected utility after they thoroughly assess their utility function for the relevant consequence

(Wallenius et al. 2008). Moreover, utility is a measure of desirability of satisfaction and practical effectiveness of a service or product (Stewart and Mohamed 2002). Utility functions are a key to customer acceptance of technology because customers’ perception of technology is critical to organization's strategic decisions. Technology utility is also associated with its usefulness. The user will tolerate some difficulty in using technology as long as it seems to be useful. However, 
the implementation is more likely to fail if the user does not find utility from its use (Mozeik et al. 2009). Wang et al. (2012) found that a customer has a positive attitude toward a self-service technology if it is perceived to be easy to use, controllable, and useful. However, if customers are forced to use a self-service technology, it directly leads to negative attitudes toward using technology and the service provider (Reinders et al. 2008, Froehle and Roth 2004). See, for example, the US Airways example in $§ 1$. Another study finds that people still place little value on cell phone-based payment systems (Dixon et al. 2009). In spite of strong efforts to develop smart card payment or smart card technology, it does not seem to provide enough utility for customers to use. Despite the operational efficiency benefits for the financial firm and its business partners, there are still many concerns regarding security and transaction costs in using smart card-based payment (Dahlberg and Mallat 2002), which may offset the perceived convenience benefits for many customers.

Thus, it is critical for organizations to evaluate and understand the perceptions and behavioral response of customers to technology attributes in services. Coinciding with the extensive adoption of technologies in service, it is imperative that decision makers obtain a better understanding of customer preferences. Technologies — aligned with the market and service bundle valued by customers_-play a critical role for organizations to be competitive on new experience-based business models (Voss et al. 2008, Roth and Menor 2003). The core dimensions that measure customer perception of any electronic delivery channel, for example, are efficiency, reliability, fulfillment, and privacy (Zeithaml 2002). Previous research finds that adoption or rejection of technology in service delivery is moderated by the personal capacity and willingness of customers (Walker et al. 2002). Other variations of customer preferences on technology include their perceptions of the complexity, the uncertainty of outcome, and customer 
understanding and knowledge of technology (Durkin et al. 2003, Huete and Roth 1988). Wang et al. (2012) also found that situational influences (e.g., perceived waiting time, perceived task c complexity, and companion influences and past experience) impact customers' attitudes and behaviors toward self-service technology.

Service and management scholars assert that in order for a new technology system to be widely accepted, service firms should increase perceived customer value by providing appropriate solutions that can link both customer preferences and the financial success of service firms (Dahlberg and Mallat 2002, Verma et al. 1999). Moreover, service firms should develop effective process design, such as service facilities and service characteristics, to support customer preferences (Verma et al. 1999).

\subsection{Technology-Based Innovations in Service Industry}

How customers perceive and interpret a service encounter is critical to obtaining a managerial understanding of how customers react to the delivered service bundle (Chase and Dasu 2001). Froehle and Roth (2004) showed that the desire for high-quality customer service is not restricted solely to face-to-face encounters because of technological advancement. Service organizations increasingly invest their capital expenditures in service delivery technology to improve quality of the service (Joseph and Stone 2003). The service-profit chain model would predict this: infusions of technology, which enhance the customer's total experience, also act to increase the service provider's satisfaction (Heskett et al. 1997). According to the Technology Infusion Matrix (Bitner et al. 2000), three drivers of service encounter satisfaction are customization/flexibility, service recovery, and spontaneous delight. If technology is properly implemented, organizations can achieve great profitability and customers' perceptions and 
convenience also increase resulting in high customer value. An example is mobile banking. Customers have access to their accounts with their personal device to review their monthly statements and even deposit checks. Some organizations offer customization service on their website. For example, AT\&T customers can always log on to their account to change the features of their rate plans and manage their account. Many software applications and databases can be used as the means to recover service from failure quickly. Technology also allows service organizations to effectively delight their customers by using their extensive customer information database to deliver more personalized services. For example, hotels provide free room service or offer free beverages or food for their frequent customers (Bitner et al. 2000). Moreover, technology often allows employees to serve customers more efficiently by providing information and data; in turn, either employees can improve the quality of their interactions with their customers or firms may support customers with what they need without the existence of service employees (Roth et al. 1995). The delivery system of a service organization comprises both the service and delivery channels in retail banking (Huete and Roth 1988). These authors showed empirically those customers' preferences toward a technology channel in retail banking were influenced by service complexity and customer knowledge. Notably, Shockley et al. (2015) showed similar results for successful retail store design. Huete and Roth (1988) demonstrated that the service bundle is what is actually delivered to customers through various sociotechnical delivery channels. For example, people can book a hotel room (service content) through online reservation (a delivery channel) at a discounted price. Any technologies that are used to deliver service to customers are concerned with the efficient way of where, when, and how the service content is delivered to the customer. The contribution of service delivery channels have been studied extensively, especially in banking (Huete and Roth 
1988, Menor and Roth 2007, Karjaluoto et al. 2002, Patricio et al. 2003, Xue et al. 2007). The availably extensive delivery channels for bank customers offer the potential for high-quality, timely, and complimentary service. Notably, organizations are able to develop a deep understanding of customer behavior by actively using technology-based service because customer activities can be recorded in real time, saved, and analyzed (Iqbal et al. 2003).

\section{Research Methodology}

To examine customer preferences and usage for technology-based innovations in services, we followed the research methodology described in §§3.1-3.4. This section describes the study context, research design, data collection, and analytical procedures in our research.

\subsection{Study Context}

To assess empirically customer value based on usage and utility that are associated with the deployment of customer interfacing technologies, we studied the restaurant industry within the United States. This sector provides a useful context because of the wide spectrum of customer interfacing technologies being used in various stages of service delivery and because restaurants offer a range of service types, from quick service to full service. A 2013 study of restaurant executives provides a service providers’ view of technology adoption (Lorden and Pant 2014). These authors report that the respondents manage or own more than 30,250 restaurants (as of 2013), of which 55 percent are quick service and 45 percent are full service. Executives reported an increasing interest in using technology in their restaurants; therefore, they are investing a larger portion of their budget and other resources across all restaurant types to better innovate their service delivery systems through technology. Importantly, these executives 
prioritized customer-facing technology, followed by other front- and back-room technologies. With continuous development of technology, restaurant executives aim not only to be more productive and efficient, but also to achieve greater customer satisfaction.

Taking a customer view, many rely on online information restaurants provide to find the location or review menus with their smartphones or tablets. This trend becomes more obvious among younger consumers because of wide diffusion of technology gadgets. Also, customers find that many restaurants have started to implement increasingly more in-store, customer-facing technology to improve the service speed and effectively manage service flows. For example, some self-activated systems for food ordering and payment are being used mostly by younger adults because such technology allows them to control certain aspects of their dining experience. Restaurant managers expect that tableside ordering and payment systems, such as iPad/tablet menus and touchscreen kiosks, will be offered more widely across all segments of restaurants (Lorden et al. 2012). Not only that, more than 90 percent of restaurant managers are actively involved with social media marketing through Facebook and Twitter to promote their business and get in touch with their communities. These industry and customer trends signal that a wider range of technology options will be available and become popular in restaurants in the future.

Although technology innovation in restaurants is high, providers face a major challenge - the high cost of implementation. Their budgets are not sufficient to meet customers' growing demands for technology, especially for $\mathrm{R} \& \mathrm{D}$ and innovation. Restaurant managers indicate that they currently spend 60 percent of their budgets on maintenance of existing systems and 17 percent on $R \& D$ and innovation (Lorden et al. 2012). They also agree that more funding should be allocated to $R \& D$ and innovation and reduce the amount of money spent on 
maintenance. Thus, the industry provides a useful setting for linking technology innovations with usage and utility.

\subsection{Research Design}

To explore the research questions described earlier, we developed and administered a survey that contained questions relating to respondents’ background, their past usage and experiences with technology-based innovations in restaurants, a Best-Worst choice experiment, and an abbreviated version of the Technology Readiness Index scale (TRI; Parasuraman 2000).

The first section of the survey asked general questions about frequency of the respondent's restaurant visit, their spending, and their approaches to choosing a restaurant. The types of restaurants are kiosk/café, fast food or quick service restaurants, fast casual restaurants, casual dining establishments, upscale casual dining establishments, and fine dining establishments. We asked respondents how often they visit each type of restaurants and how much they typically spend on average per person when they visit each type of restaurants. Then the survey asked how often respondents use different types of approaches when choosing restaurants. The options were social media (e.g., Facebook); group discount sites (e.g., Groupon and LivingSocial); review in a newspaper or a magazine; own past experiences; recommendation by friends/family; mobile phone’s location-based applications (e.g., Foursquare, Facebook places); online customer review site (e.g., Yelp, Urbanspoon, and TripAdvisor); rating by a professional source (e.g., Zagat and Michelin); and other reasons. If they have used any kinds of social media, then we specifically asked them to indicate which of sources they typically use by providing them possible names of the websites. The next section asked respondents about technology usage during their recent restaurant visits. We provided respondents 15 different 
types of technologies with a definition of each technology that is currently being used at restaurants and asked them whether they have had the opportunity to use it.

The second section of the survey included a Best-Worst (also known as maximumdifference or max-diff) choice experiment, which is a variant of the experimental discrete choice analysis (Louviere and Woodworth 1983). The Best-Worst approach requires respondents to identify alternatives in each experiment, which are respectively "Best” and "Worst" on some dimension. This approach was originally proposed by Finn and Louviere (1992) as a variant of the standard discrete choice experiment, to identify the relative position of alternatives along a continuum. Examples of such scales include ratings of alternatives along a continuum from “most important to least important,” “most preferable to least preferable,” “most satisfying to least satisfying,” “most challenging to least challenging,” and “most positive to least positive.”

Since publication of the Best-Worst approach, many scholars have compared the BestWorst experimental approach with other commonly used methods for measuring the relative importance of alternatives (e.g., Likert scales, constant sum scales, and rankings). A series of published studies conclusively demonstrate that the best-worst technique is superior to other approaches when trying to measure the relative positioning of alternatives (e.g., Chrzan and Golovashkina 2006, Louviere and Islam 2008, Marley et al. 2008, Vermeulen et al. 2010, Potoglou et al. 2011, Adamsen et al. 2013). Therefore, during the last few years, Best-Worst choice experiments have found extensive applications in a diverse range of research topics, including healthcare (see Louviere and Flynn 2010, Molassiotis et al. 2012, Marti 2012, Lancsar et al. 2013); marketing research (Casini et al. 2009, Louviere et al. 2013); food and nutrition (Mielby et al. 2012, Loose and Lockshin 2013); environmental studies (Loureiro and Arcos 2012); customer satisfaction (Garver 2009); and business ethics (Auger et al. 2007). For the first 
time, our paper uses the results from Best-Worst experiments to develop a numerical taxonomy of technology clusters of customers that provide valuable insights into linking customer strategic groups (as segments) to technology attributes valued by customers.

Although the use of standard discrete choice experiments is also used to some extent in operations management (OM) — for example, to explore product/service design (Verma et al. 2006, Iqbal et al. 2003, Victorino et al. 2005); labor scheduling (Goodale et al. 2003); and supplier selection (Li et al. 2006, Rhee et al. 2009)—-the Best-Worst or max-diff approach specifically has not been used in OM research to date. Utility theory provides the theoretical basis for discrete choice analysis (DCA; Louviere 1988). Human choice behavior can be determined from a set of choices containing finite alternatives. A person gets to choose the alternative that provides him or her the highest value based on subjective judgements. Hence, considering the Best-Worst analysis, similar to standard discrete choice analysis, the relative weights (or utilities) of choosing an alternative from a given set of choice can be expressed by using a multinomial logit (MNL) (McFadden 1986). DCA can be an important methodology for service organizations to understand the customers’ relative importance of various service attributes and realize the customer choice and demand (Verma et al. 1999). With this powerful methodology of understanding customers' utility, organizations should be able to manage their operations more effectively by accurately forecasting customer demand and offering service configuration that reflects customers' utility.

In our survey, we conducted Best-Worst experiment to measure customers’ utility in using various customer-facing service technologies. Each respondent was shown six Best-Worst choice sets of management challenges that were generated by the max-diff module of the Sawtooth Software (http://www.sawtoothsoftware.com/products/maxdiff-software). Each screen 
included lists of seven managerial challenges where the respondent was asked to identify the most and the least important. The Best-Worst experiment was designed in such a manner that each respondent saw a completely different sequence and mix of criteria of each screen.

Furthermore, we ensured that on average each criterion appeared an equal number of times on best-worst screens for each respondent. A sample Best-Worst exercise screenshot can be seen in Figure 1.

The third part of the survey included a 10-item abbreviated Technology Readiness Index (TRI; Parasuraman 2000) to estimate each respondent’s TRI score. Accordingly, as originally envisioned, TRI determines a person’s perception of readiness to use new technologies by proposing a construct comprised of four dimensions: optimism, innovativeness, discomfort, and insecurity. In our study, for each of the 10 TRI items capturing their general perceptions of technology, respondents rated them on a five-point Likert-type scale, with possible responses ranging from “1Dstrongly disagree” to “5Dstrongly agree” (Likert 1932). Finally, in the last section of the survey, respondents were asked demographic questions (e.g., age and gender).

\subsection{Data Collection}

The focus of this research was to understand customers' usage and utility for customerfacing technology-based innovations within the context of U.S. restaurant industry. To identify relevant samples of respondents, we received assistance from TripAdvisor, a travel site helping travelers to plan their trips in advance. TripAdvisor is considered to be one of the leading customer feedback social media websites and is one of the most widely visited hospitality-related websites (Miguens et al. 2008). TripAdvisor was founded in 2000 and now operates in 39 countries worldwide while managing websites under 21 other travel media brands. It also 
provides access worldwide to leading online travel agencies including Expedia, Orbitz, Travelocity, and more. On its websites, visitors can read reviews and opinions from travelers around the world and find hotels, restaurants, and vacation rentals. Travelers can also customize their trips by adding maps, photos, and travel plan details. Then TripAdvisor sends travelers customized e-mail alerts on the specific hotels, restaurants, destinations requested by the traveler.

In 2013, TripAdvisor launched our survey to a randomly selected sample of approximately 3,000 customers from the United States from its vast database of millions of users of its site. We received 1,093 useable surveys for our analysis, yielding approximately a 33 percent rate. Because the data were provided to us directly by TripAdvisor, we had no opportunity to perform a formal analyses of possible response bias; therefore, we view our sample as volunteer in nature and our study exploratory. Such samples are useful in pioneer stage of research such as this. Respondent demographics are summarized in Table 1. More than half of the respondents in the study were female and 45 years of age and older. Analysis of the data revealed that most respondents had a college degree or higher, indicating that they are well educated. The sample also included a range of incomes, with nearly half of the individuals making more than $\$ 100,000$ dollars a year.

\subsection{Analysis Approach}

3.4.1 Restaurant Technologies. As mentioned earlier, the utility for different types of technology-based innovations were identified by using a best-worst experiment. Therefore, similar to a standard discrete choice analysis, a MNL model was used to identify the relative weights (or utilities) of each alternative in a Best-Worst choice experiment (McFadden 1986). A descriptive paper by Verma et al. (1999) describes how MNL models are developed for discrete 
choice experiment, and Finn and Louviere describe how it can be adapted for a Best-Worst experiment (Finn and Louviere 1992). Rather than repeating this well-established information from the related research methodology literature, we describe the results and its implications related to our research questions. In the current research, we used Sawtooth Software's hierarchical Bayes estimation technique to identify utilities for each type of restaurant technologies for each customer (Orme 2009).

Our survey also included questions about past implementation of different types of technologies. We asked the respondents to indicate if they had used them in the past. To reduce the dimensionality of number of technologies, we conducted a principal component analysis (PCA) in SPSS 18 on the 15 different types of technologies depicted in Table 2 that are currently being used at restaurants to observe if some technology items might load on the fundamental dimensions assumed to underlie the original variables (Hair et al. 1998). By using PCA, researchers can reduce a large set of variables to a smaller set of variables to simplify the analysis, and the new variables still carry characteristics of the original variables (Hair et al. 1998). This analysis revealed five factors with eigenvalues greater than one, which is the traditional cutoff value; it also passed the Scree test (Hair et al. 1998). Next, we applied varimax rotation. We interpreted our five technology factors as (1) queue management, (2) payment, (3) kiosk-based, (4) mobile-based, and (5) tablet-based, (Table 2). These five technology factors carry the common characteristics of the original variables. Our results corresponded closely to those found in prior research by Dixon et al. (2009), using PCA on a different customer sample with some slightly different technologies. These authors examined 11 different types of restaurant technologies and found them to fall into one of five categories: queue management, 
payment, kiosk, Internet-based, and menu (Dixon et al. 2009). The two factors that differed from ours were "Internet-based” and “menu.”

3.4.2. Cluster Analysis Procedures. Cluster analysis was implemented, using the five technology types derived from our PCA analyses as taxons, on restaurant customers' usage and utility for these technologies. The resulting strategic customer groups from our clustering procedure allow us to classify customers according to their relative patterns of technology usage and utility. Before running cluster analysis, however, we conducted multivariate analysis to detect outliers in our sample using the method of Mahalanobis D2 measure (Hair et al. 1998). One restaurant customer with a Mahalanobis distance probability smaller than 0.001 was deleted, leaving us with an effective sample size of 1,093. We then standardized original variables into a new variable with a mean of 50 and a standard deviation of 10 to compare the relative effect of each usage and utility variable directly, as they were originally captured on different measurement scales. Next, we adopted a two-step approach using SAS 9.3, the Approximate Covariance Estimation for CLUStering (ACECLUS) and the FASTCLUS procedure (Miller and Roth 1994, Rosenzweig et al. 2011). The ACECLUS procedure obtains approximate estimates of the pooled within-cluster covariance matrix of samples, using the five categories of technology usage and utility score. Then the FASTCLUS procedure was followed to perform a disjoint cluster analysis on the basis of Euclidean distances, often called a k-means procedure (Punj and Stewart 1983).

To determine the most appropriate number of clusters, we looked for significant increases in the tightness of the clusters measured by the $R^{2}$ and pseudo $-F$ statistic. We also considered managerial interpretability of the cluster solutions based on ANOVA and Tukey pairwise comparison tests of cluster mean differences. The four cluster model best satisfied these criteria. 
Results from an overall multivariate test of significance using the Wilk’s lambda criterion and the associated $F$ statistic indicated the null hypothesis that four clusters are equal across all defining variables could be rejected $(F-$ value $D=45.25, p<000001)$.

\section{Results}

In this section, we report the strategic customer groups based on technology usage and utility taxons. Interestingly, the strategic groups profiled on technology usage in Table 3 appear to align themselves around characteristics of the technology itself (i.e., physical devices, virtual devices, or functional devices) or they tended not to favor technology generally (low users). In contrast, the strategic customer groups classified on utility found intrinsic value with technologies that were associated with the distinct aspects of the process that they wished to control (i.e., technology was valued along dominant locus of control characteristics).

\subsection{Restaurant Strategic Customer Groups: Technology Usage}

The four resulting groups of restaurant customers are described in Table 3 in terms of cluster centroid (mean) scores and their relative ranking in the set of five categories of usage dimensions identified by PCA. The results of Tukey pairwise comparison tests are also described to show which groups significantly differ from others $(\mathrm{p}<0005)$. The four strategic technology usage groups are named "physical device users," "virtual users” “functional device users,” and “lower users.” Notably, customers represented within each particular usage group tend to have a preference for the nature of the devices used.

Cluster 1: Physical Device Users. We label cluster 1 the “physical device users” because based upon its relative rank, usage of tablets and kiosks appears to be the dominant categories of 
technology for the members of cluster 1. Compared to other categories of technology, tablets and kiosks are the actual physical devices that allow customers to order their meals or pay their bills. Technologies used for payment such as a smart phone or a smart credit card and pagers for waittime management were rated significantly below the importance given by cluster 3. These types of technologies are used for the purpose of functional use by restaurants. The 106 members of cluster 1 represent 10 percent of restaurant customers in our sample.

Cluster 2: Virtual Device Users. The virtual device users distinguish themselves from every cluster group on mobile-based types of technologies. Also, mobile-based technologies appear to be the highest relative rank among other types of technology in this cluster. Restaurant customers in this group probably want to have more behavioral control over the dining out experience by choosing what and when they would like to eat through mobile applications with their own devices. Although mobile-based type of technologies has less appearance or form of a device than tablets or kiosks, it still has the essence of impact on customers allowing them to have more control over the service. The 173 restaurant customers in this group account for 16 percent of restaurant customers in our sample.

Cluster 3: Functional Device Users. We label this group “functional device users” because cluster 3 members are differentiated by the relatively high rank on technologies that are related to payment and controlling queue. Customers in this group highly use technologies that have a special purpose or task for efficient service operation. For example, pagers for wait-time management provide customers with notice of when a table is available, or online table reservation assures customers that they do not have to wait in line. These types of technologies not only increase product and service consistency but also increase customers’ cognitive control. The functional device users form the second largest cluster, comprising 22 percent of the cases. 
Cluster 4: Low Users. Labeled the "low users,” cluster 4 members show a relative lowest rank in four categories of technology. While the other three clusters score relatively high in at least one category of technology, this low user group does not appear to be using any of the five categories of technology. Interestingly, low users are the largest group, accounting for about 52 percent of the cases.

\subsection{Restaurant Strategic Customer Groups: Technology Utility}

The four resulting groups of restaurant customers are described in Table 4 in terms of cluster centroid (mean) scores and their relative ranking in the set of five categories of utility dimensions identified by PCA. The results of Tukey pairwise comparison tests are also described to show which groups significantly differ from others $(p<0.05)$. The four strategic technology utility groups are named based on "Locus of control” attributes valued intrinsically by most of

customers who are represented within each cluster: “Onsite control,” “Total process control,” “Time control,” and "Tangible technology.”

Cluster 1: Onsite Control. This strategic group tend to highly value a type of technology that allows them to "control” their services inside the restaurant. Based upon its relative rank, tablet technology appears to be the customers' dominant preference for the members of cluster 1. The relative ranks of the kiosks and the payment-based technologies are also relatively high compared to other technologies. Online reservation or pagers for wait time management can be used offsite, though tablets, kiosks, and payment via smartcard/smartphones are mainly used onsite to process the delivery of service. The 256 restaurant customers in this group account for 23 percent of restaurant customers in our sample. 
Cluster 2: Total Process Control. The people in this strategic group highly value using technologies from the beginning to the end of their dining experiences by making a reservation online, ordering food with tablets, and paying with their own devices to obtain control throughout the total process of service. They prefer to manage their time with online reservation or Internet-based ordering before going to the restaurant and make a payment with their own devices. This strategic group also value tablets and pagers in a restaurant because these devices can increase cognitive control by reading nutritional information on tablets and knowing the length of their wait with pagers. Also, high customer value is placed on payment via smartcard/smartphones and mobile-based technology among restaurant customers in this group.

Although kiosks can be used as a part of process control, people in this cluster group do not perceive kiosks to be equally valuable as other technologies. One plausible reason is that customers have experience of going to a restaurant that only uses a kiosk for food ordering and payment with no other option for service delivery. With this case, customers may have been forced to use kiosks and feel that kiosks give them less control and do not allow any options. Forcing self-service technology use leads to negative attitudes toward the technology-based selfservice (Reinders et al. 2008). The 265 members of cluster 2 represent 24 percent of restaurant customers in our sample.

Cluster 3: Time Control. We name this cluster "time control” because the most valuable technology innovations within this cluster are related to queue management and mobile-based technologies. Those two technologies can significantly increase customers’ perceived time control over their freedom of movement while waiting with pagers and minimizing customers' wait time with online reservation and online pre-order. The people in this group tend to want 
time efficiency and do not want to waste their time standing in line at a restaurant. This cluster is the second largest strategic group, accounting for 25 percent of the cases.

Cluster 4: Tangible Technology. We label this group the "tangible technology" because top ranked technologies within this cluster group were pagers, tablets, and kiosks, which are more tangible devices than payment-related or mobile-based information technologies. On the other hand, cluster 4 members place significantly less importance on paying via smartcard/smartphones; they tend not to value smartcard or smartphones as another method of payment. The tangible technology group forms the largest cluster, comprising 28 percent of the cases.

\subsection{Statistical Validation}

To validate our model, multiple group discriminant analysis was performed using the SAS Candisc (canonical discriminant analysis) procedure with the four groups as dependent variables and the five different dimensions of technology usage and utility as independent variables. The results of the discriminant analysis are presented in Tables 5 and 6 . In addition, the discriminant loadings represent the correlations between the five different types of technology usage/utility taxons and their respective discriminant functions. According to Cramer and Nicewander's (1979) measure of multivariate association, $y_{6}$ is defined as the average of the squared canonical correlations. Our results indicate that 60 and 49 percent of the variance in the restaurant customer group membership are explained by the five technology usage and utility taxons, respectively, employed in our study.

We can interpret each canonical function based on the canonical loadings. According to Table 5, the first canonical technology “usage” function depicts the newly developed physical 
devices. Here the largest correlates of cluster membership have to do with the relative importance given to technology usage of kiosk and tablet. Restaurant customers scoring high in these taxons are likely to use interactive technologies that are available onsite to engage them. In contrast, they are less apt to use technologies that are mobile and Internet-based or are perhaps more passive, such as pagers to manage their waiting line or those that are relatively new that require the customer to possess the device and the "app” (e.g., mobile and payment).

Usage of mobile devices and technologies for controlling queue (including onsite pagers and offsite Internet reservations/ordering) are positively correlated with canonical function 2. These two taxons represent examples of relatively new mobile technologies and apps for restaurants. Customers scoring high for usage on these taxons are more likely to want some control over their time and decision making (Dixon et al. 2009). Given high canonical loadings in usage of mobile device, customers falling in this membership might want to increase their behavioral control by reserving a seat on the Internet and deciding a meal even before they go to the restaurant. These customers seem to be interested in using technologies that can improve their convenience or minimize their wait times from anywhere at any time. Finally, the third canonical function in Table 5 implies differentiation of restaurant customers by functional uses for technology—payments and queue management.

The canonical functions for technology utility (Table 6) differ from those observed for usage in Table 5. One observation is that Table 6 includes highly correlated negative taxon values with the function as well as positive ones. This result indicates that customers are simultaneously predisposed toward having a high preference for certain positive attributes and substantially inclined to place a low value on others. In canonical function 1 (Table 6), customers place a premium on kiosks, whereas they seem distance themselves from mobile and payment 
technologies. They appear to value the speed and convenience of an onsite, self-service technology in a restaurant (with little employee contact), which may be analogous to some banking customers’ preference for self-service ATMs, but they are highly adverse to more virtual, advanced technologies (Xue et al. 2007).

Customers represented by canonical function 2 (Table 6) prefer onsite tablets for their restaurant experience and at the same time, they are highly adverse to mobile and queue-type technologies. They seem to value the onsite tablet experience and dislike (or distrust) virtual encounters with restaurants.

Canonical function 3 (Table 6) reveals a group of customers who place much value on kiosks and payments systems. This group also likes convenience and speed at the front- and back-end of the service. Moreover, customers that like payment technologies and perhaps are more secure with them in contrast to customers in canonical function 1 . Interestingly, this group does not value tablet-based technologies.

\subsection{Statistical Cross-Validation}

To determine the stability of the estimates, we performed jackknife discriminant analysis procedures cross-validation in SAS. Tables 7 and 8 show the results of the cross-validation procedure for the usage and utility strategic groups, respectively. The overall error rate from cross-validation is 0.04 for both technology usage and utility, reflecting that five technology usage and utility taxons, respectively, perform well in classifying restaurant customers. 


\subsection{Cross-Tabulation}

The new taxons from customers' technology usage and utility derived from two different cluster analyses are placed in a contingency table to examine the relationship between two taxons. Next, we calculate a measure of association or similarity between technology usage and utility by using chi-square value. In our study, we have four different usage taxons and four different utility taxons, each derived from five technologies (Table 9). The chi-square test shows that cluster membership of technology utility is associated with that of technology usage $\left(x^{2}=\right.$ 61.485, $d f=9, p=0.000$ ). The plausible explanation of the relationship between utility and usage is that customer utility might increase if customers have already used the technology in the past (Dixon et al. 2009). The relationship between customer usage and utility is discussed in detail in $\S 5$.

\subsection{Other Associated Factors}

To further determine the differences among cluster memberships for usage and utility, we conducted Tukey pairwise comparisons with other important variables provided by TripAdvisor (see Tables 10 and 11). The variables employed for our study are frequency of visits to different types of restaurants, their TRI score, usage of social media, and demographic factors.

4.6.1. Strategic Usage Groups. In terms of their past behavior of going to restaurants, physical device users and virtual device users are more frequent diners than are the other two groups. The result implies that although kiosk and tablet are readily available at cafés or fast casual restaurants, mobile applications and mobile websites are widely used at fast casual or casual dining restaurants. Attesting to the face validity of our cluster result, the low user group had the lowest TRI score and virtual device users, the highest TRI score. Virtual device users are 
interested in experimenting with different types of technology with their own devices. For example, virtual device users can use their mobile phone’s location-based application, such as Foursquare or Facebook, or online customer review sites, such as Yelp, Urbanspoon, and TripAdvisor.

Regarding demographics, the strategic usage groups offer insight into their relative involvement with technology. While we did not find a gender difference among four technology user groups, not surprisingly, we did find that physical and virtual device users are younger than either the functional device or low user group, indicating that younger people are more actively engaged with technology. Adding face validity to our results, we found that customers with higher incomes are virtual device users, indicating that they can afford their own mobile devices and the ongoing telecommunications service fees.

4.6.2. Strategic Utility Groups. Most fast food restaurants now have facilitated convenience by installing kiosks or tablets. The onsite control group perceives these technologies to be highly valuable, perhaps for convenience, customization, and service control. On the other hand, total process control group tends to prefer casual, upscale casual or fine dining establishments; they highly value controlling the reservations and ordering processes by using technologies, and wanting a technology-free dining experience. The total process control group also shows the highest TRI score and the tangible technology group shows the lowest. Also, total process control group receives benefits of using social media by a professional source such as Zagat or Michelin. Particularly intriguing is that we did not find significant demographic differences among four technology utility groups except for age and income, which does not bode well for traditional market segmentation on these characteristics when it comes to customer value through technology. 


\section{Discussion}

Previous research finds, in general, that technology innovation in service impacts customers’ choices (e.g., service channels and usage; see Xue et al. 2007) and generally results in financial performance benefits for an organization. The importance of technology innovation in the service industry has been long been recognized by academia and practitioners.

\subsection{Theoretical Contributions}

We performed the clustering procedure on the collected data on technology usage and utility and developed numerical taxonomies. Numerical taxonomies have been used extensively in the field of science to classify various types of objects in a concise form so our study contributes to strategic aspects of science systems. The customer usage and utility taxonomies developed here can help researchers structure a dynamic field of service science and facilitate its understanding of customer value in a more organized way. Four taxons of usage reflect what service providers offer for their customers, while four taxons identify customers' intrinsic value or utility. Interestingly, our study revealed that strategic customer groups built on usage tend to emphasize different types of technology functionality, whereas those on customer utility are fundamentally different in that they draw upon the "locus" of control that customers value most. Bolton and Drew (1991) assert that a customer's assessment of service value differs among customers because of differences in customers' level of sacrifice in terms of their perception of benefits gained in exchange for the costs, customers’ characteristics, and customers’ various tastes. Our study extends the scope of customer's utility by classifying them into four distinctive segments of customer perceived value and examines what commonalities each group shares and what characteristics make each group distinct. Thus, service providers in planning their strategic 
customer-facing technologies should align them with type of "control/benefits” that their target market customers value most. The commonalities or characteristics within each group, on average, will indicate the underlying competitive factors in terms of assessing technology in service industry. Our research also suggests that taxonomy of customer value can be a contributing factor to service science by synthesizing findings with other research of service designs or service strategic technology choices. The results provide a platform for further research on how various dominant customer utility groups influence business performance outcomes in different types of services and customer-facing technologies.

An important methodological contribution of this study is an implementation of BestWorst experiment used to analyze the customer utility in terms of technological innovations in service industry. Individuals’ utility score reflects their intrinsic valuation of technology and how they perceive technology innovations in service industry. The development of such methodology allows researchers to carefully examine what customers value and what underlying market drivers can potentially increase customer value in the future. Overall, the methodology offers the service science discipline a means of determining customer value and then provides an approach to segment customers based on their utility scores.

\subsection{Managerial Contributions}

The relationship between usage and utility of technology innovations we have identified plays an important role in the design and development of organization's technological innovations. Without a thorough understanding of customers' valuation of technology innovations, it would be pointless for organizations to invest more in the development of technology. Our empirical results showed that customers' high usage in a specific technology 
does not uniformly lead to customers' high utility for that technology as well. If service practitioners use customers' usage data as a proxy in forecasting customers' utility, they will likely be on the wrong track of understanding customers' intrinsic value. In other words, higher customer usage, while associated, does not necessarily translate directly into higher customer utility. For example, some quick service restaurants at the airport only facilitate a kiosk for customers to order their food. The customer has no choice but to order their food via kiosk, even if they preferred not to when no other options are available. Although usage data can be partially useful in a monopoly situation, utility captures what customers actually value. A gap between what is available and what customers want opens the doors for savvy competitors. Thus, organizations should find a more effective way to assess customer utility rather than customer usage for market segmentation and design the customer facing technologies for their target customers (Roth and Menor 2003). The knowledge and information on customer utility segments should be translated into effective operational decisions and process design (Verma et al. 1999).

Also, our study empirically shows that respondents do not consider every technological innovation to be equally valuable, which may impact the firm's customer-facing technology choices. As gleaned from Table 4, we find the average utility scores in each segment are not equal. It is more likely that customers place a higher value on technologies if they are already familiar with them or they are easy to use. One study reveals that customers' perceived value tends to increase if they have used an assigned technology previously (Dixon et al. 2009). Therefore, knowledge of strategic user groups may play a “qualifier” role in service strategy deployment of technology. It is important for service providers to ensure that the new technologies are “user friendly,” “intuitive,” and “easy to use.” Service providers should also provide their customers with good demonstration and customer support until customers become 
familiar with the new technology (Dixon et al. 2009). In addition, a new customer-facing technology that can increase customers’ efficiency and improve communications may, over time, increase its value among customers, resulting in high customer satisfaction and service quality (Xue et al. 2007, Roth et al. 1995, Huete and Roth 1988).

\section{Conclusions}

Although our study provides a relationship between technology usage and utility based on individual's characteristics, there are limitations in our conclusions. Our data are limited to the restaurant industry in the United States; we are limited to secondary data supplied by TripAdvisor. It might bring an issue of generalizability of the results. It would yield different results of usage and utility of technology innovations if we study other service industries. Therefore, cross-cultural or different service segment studies would help the generalizability of the results. Also, social media awareness, for example, would be a critical predictor in service organizations with the continuous development of technology. Future research should include more concepts exploring the relationship between use and value in detail.

Overall, technological innovation can be one of the most competitive weapons in a service industry. Our goal was to examine a customer's usage and utility of technology innovations in a setting of a restaurant industry. By doing so, our study bridges services operations and marketing strategy. Especially through the deployment of utility-based, strategic customer groups (in contrast to usage groups) to guide market segmentation, operational technology adoption and implementation may be more effective. We find that customers have distinct differences with regard to technology usage and utility based on their demographic characteristics, past behavior of dining out experiences, and TRI score. Therefore, in the 
development and execution of a service operations strategy, and in associated research relative to technology choices, it is essential to first recognize that usage is not a good proxy for customer value when determining whether a specific customer-facing technology actually creates customer value. Services should not follow the proverbial bandwagon when choosing their customer facing technologies but rather align their specific technology choices dynamically with characteristics favored by their targeted customers. In conclusion, our empirical results from this exploratory research suggest the following: neither service science scholars nor practitioners should assess customer value solely on usage. However, this study indicates that technology usage may be a necessary precursory condition, but it is not sufficient gauge of what actually is valued by customers. Our results shed new light on how service providers can develop their customer-facing capabilities around customer intrinsic values and in turn advance more innovative and user-friendly technology to positively affect customers’ service experiences. 


\section{Acknowledgments}

The authors thank the Cornell Center for Hospitality Research, TripAdvisor, the National Restaurant Association, and Coyle Hospitality Group for providing background information and access to customer databases for this research project. 


\section{References}

Adamsen JM, Rundle-Thiele S, Whitty JA (2013) Best-worst scaling...reflections on presentation, analysis, and lessons learnt from case 3BWS experiments. Market Soc. Res. 21(1):9-27.

Auger P, Devinney TM, Louviere JJ (2007) Using best-worst scaling methodology to investigate consumer ethical beliefs across countries. J. Bus. Ethics 70(3):299-326.

Bitner MJ, Brown SW, Meuter ML (2000) Technology infusion in service encounters. J. Acad. Marketing Sci. 28(1):138-149.

Bolton RN, Drew JH (1991) A multistage model of customers’ assessments of service quality and value. J. Consumer Res. 17(4):375-384.

Borle S, Singh SS, Jain DC (2008) Customer lifetime value measurement. Management Sci. 54(1):100-112.

Casini L, Corsi AM, Goodman S (2009) Consumer preferences of wine in Italy applying bestworst scaling. Internat. J. Wine Bus. Res. 21(1):64-78.

Chase RB, Dasu S (2001) Want to perfect your company’s service? Use behavioral science. Harvard Bus. Rev. 79(6):78-84.

Chrzan K, Golovashkina N (2006) An empirical test of six stated importance measures. Internat. J. Market Res. 48(6):717-740.

Cramer E, Nicewander WA (1979) Some symmetric invariant measures of multivariate association. Psychometrica 44(1):43-54.

Dahlberg T, Mallat N (2002) Mobile payment service development-Managerial implications of consumer value perceptions. Presentation, Eur. Conf. Inform. Systems, June 6-8, Gdansk, Poland. 
Davidow WH, Uttal B (1989) Service companies: Focus or falter. Harvard Bus. Rev. 67(4):77_ 85.

Ding X, Verma R, Iqbal Z (2007) Self-service technology and online financial service choice. Internat. J. Service Indust. Management 18(3):246-268.

Dixon M, Kimes SE, Verma R (2009) Customer preferences for restaurant technology innovations. Cornell Hospitality Rep. 9(7):4-16.

Drucker PF (1974) Management: Tasks, Responsibilities, Practices (Harper \& Row, New York).

Durkin M, McCartan-Quinn D, O’Donnell A, Howcroft B (2003) Retail bank customer preferences: Personal and remote interactions. Internat. J. Retail Distribution Management 3(4):177-189.

Ervasti M (2013) Understanding and predicting customer behavior: Framework of value dimensions in mobile services. J. Customer Behav. 12(2-3):135-158.

Estrella-Ramon AM, Sanchez-Perez M, Swinnen G, Vanhoof K (2013) A marketing view of the customer value: Customer lifetime value and customer equity. South African J. Bus. Management 44(4):47-64.

Finn A, Louviere JJ (1992) Determining the appropriate response to evidence of public concern: The case of food safety. J. Public Policy Marketing 11(2):12-25.

Fishburn PC (1968) Utility theory. Management Sci. 14(5):335-378.

Froehle CM (2006) Service personnel, technology, and their interaction in influencing customer satisfaction. Decision Sci. 37(1):5-38.

Froehle CM, Roth AV (2004) New measurement scales for evaluating perceptions of the technology-mediated customer service experience. J. Oper. Management 22(1):1-21. 
Garver MS (2009) A maximum difference scaling application for customer satisfaction researchers. Internat. J. Market Res. 51(4):481-500.

Goodale JC, Verma R, Pullman ME (2003) A market-utility approach to scheduling employees. Cornell Hotel Restaurant Admin. Quart. 44(1):61-69.

Gupta S, Hanssens D, Hardie B, Kahn W, Kumar V, Lin N, Ravishanker N, Sriram S (2006) Modeling customer lifetime value. J. Service Res. 9(2):139-155.

Hair JF, Anderson RE, Babin BJ, Black WC, Tatham RL (1998) Multivariate Data Analysis, 7th ed. (Prentice Hall, Englewood Cliffs, NJ).

Heskett JL (1987) Lessons in the service sector. Harvard Bus. Rev. 65(2):118-126.

Heskett JL, Sasser WE, Schlesinger LA (1997) The Service Profit Chain: How Leading Companies Link Profit and Growth to Loyalty, Satisfaction, and Value (Free Press, New York).

Holcomb MC (1994) Customer service measurement: A methodology for increasing customer value through utilization of the Taguchi strategy. J. Bus. Logist. 15(1):29-52.

Huete L, Roth AV (1988) The industrialization and span of retail banks delivery systems. Internat. J. Oper. Production Management 8(3): 46-66.

Iqbal Z, Verma R, Baran R (2003) Understanding consumer choices and preferences in transaction-based e-services. J. Service Res. 6(1): 51-65.

Joseph M, Stone G (2003) An empirical evaluation of US bank customer perceptions of the impact of technology on service delivery in the banking sector. Internat. J. Retail Distribution Management. 31(4):190-202.

Karjaluoto H, Mattila M, Pento T (2002) Factors underlying attitude formation towards online banking in Finland. Internat. J. Bank Marketing 20(6):261-272. 
Lancsar E, Louviere JJ, Donaldson C, Currie G, Burgess L (2013) Best-worst discrete choice experiments in health: Methods and an application. Soc. Sci. Medicine. 76(1):74-82.

Levitt T (1972) Production-line approach to services. Harvard Bus. Rev. 50(5):41-50.

Li S, Madhok A, Plaschka G, Verma R (2006) Supplier-switching inertia and competitive asymmetry: A demand-side perspective. Decision Sci. 37(4):547-576.

Likert R (1932) A technique for the measurement of attitudes. Arch. Psych. 140(5):1-55.

Loose SM, Lockshin L (2013) Testing the robustness of best-worst scaling for cross-national segmentation with different numbers of choice sets. Food Quality Preference 27(2):230242.

Lorden AA, Pant G (2014) 16th annual restaurant technology study. Report, Hospitality Technology, Randolph, NJ.

Lorden AA, Pant G (2015) 17th annual restaurant technology study. Report, Hospitality Technology, Randolph, NJ.

Lorden AA, Cobanoglu C, Berezina K, Erdem M, Nusair K (2012) 14th annual restaurant technology study. Report, Hospitality Technology, Randolph, NJ.

Loureiro ML, Arcos FD (2012) Applying best-worst scaling in a stated preference analysis of forest management programs. J. Forest Econom. 18(4):381-394.

Louviere JJ (1988) Conjoint analysis modeling of stated preferences: A review of theory, methods, recent developments and external validity. J. Transport Econom. Policy 22(1):93-119.

Louviere JJ, Flynn TN (2010) Using best-worst scaling choice experiments to measure public perceptions and preferences for healthcare reform in Australia. The Patient: PatientCentered Outcomes Res. 3(4):275-283. 
Louviere JJ, Islam T (2008) A comparison of importance weights and willingness-to-pay measures derived from choice-based conjoint, constant sum scales and best-worst scaling. J. Bus. Res. 61(9):903-911.

Louviere JJ, Woodworth G (1983) Design and analysis of simulated consumer choice or allocation experiments: An approach based on aggregate data. J. Marketing Res. 20(4):350-367.

Louviere JJ, Lings I, Islam T, Gudergan S, Flynn T (2013) An introduction to the application of (case1) best-worst scaling in marketing research. Internat. J. Res. Marketing 30(3):292303.

Marley AAJ, Flynn TN, Louviere JJ (2008) Probabilistic models of set-dependent and attributelevel best-worst choice. J. Math. Psych. 52(5):281-296.

Marti J (2012) A best-worst scaling survey of adolescents’ level of concern for health and nonhealth consequences of smoking. Soc. Sci. Medicine 75(1):87-97.

McFadden D (1986) The choice theory approach to market research. Marketing Sci. 5(4):275297.

Menor LJ, Roth AV (2007) New service development competence in retail banking: Construct development and measurement validation. J. Oper. Management 25(4):825-846.

Mielby LH, Edelenbos M, Thybo AK (2012) Comparison of rating, best-worst scaling, and adolescents’ real choices of snacks. Food Quality Preference 25(2):140-147.

Miguens J, Baggio R, Costa C (2008) Social media and tourism destinations: TripAdvisor case study. IASK ATR 2008, Adv. Tourism Res., Aveiro, Portugal, 1-6.

Miller JG, Roth AV (1994) A taxonomy of manufacturing strategies. Management Sci. 40(3):285-304. 
Molassiotis A, Emsley R, Ashcroft D, Caress A, Ellis J, Wagland R, Bailey CD, et al. (2012) Applying best-worst scaling methodology to establish delivery preferences of a symptom supportive care intervention in patients with lung cancer. Lung Cancer 77(1):199-204.

Morgan RM, Hunt SD (1994) The commitment-trust theory of relationship marketing. $J$. Marketing 58(3):20-38.

Mozeik CK, Beldona S, Cobanoglu C, Poorani A (2009) The adoption of restaurant-based eservice. J. Foodservice Bus. Res. 12(3):247-265.

Orme B (2009) Maxdiff analysis: Simple counting, individual-level logit, and HB. Report, Sawtooth Software, Orem, UT.

Paananen A, Seppanen M (2013) Reviewing customer value literature: Comparing and contrasting customer value perspectives. Intangible Capital 9(3):708-729.

Parasuraman A (1997) Reflections on gaining competitive advantage through customer value. $J$. Acad. Marketing Sci. 25(2):154-161.

Parasuraman A (2000) Technology readiness index (TRI) a multiple-item scale to measure readiness to embrace new technologies. J. Service Res. 2(4):307-320.

Patricio L, Fisk RP, e Cunha JF (2003) Improving satisfaction with bank service offerings: Measuring the contribution of each delivery channel. Managing Service Quality 13(6):471-482.

Potoglou D, Burge P, Flynn T, Netten A, Malley J, Forder J, Brazier JE (2011) Best-worst scaling vs. discrete choice experiments: An empirical comparison using social care data. Soc. Sci. Medicine 72(10):1717-1727.

Punj G, Stewart DW (1983) Cluster analysis in marketing research: Review and suggestions for application. J. Marketing Res. 20(2):134-148. 
Reinders MJ, Dabholkar PA, Frambach RT (2008) Consequences of forcing consumers to use technology based self-service. J. Service Sci. 11(2):107-123.

Rhee B, Verma R, Plaschka G (2009) Understanding trade-offs in the supplier selection process: The role of flexibility, delivery, and value-added services/support. Internat. J. Production Econom. 120(1):30-41.

Rosenzweig ED, Laseter TM, Roth AV (2011) Through the service operations strategy looking glass: Influence of industrial sector, ownership, and service offerings on B2B emarketplace failures. J. Oper. Management 29(1-2):33-48.

Roth AV, Menor LJ (2003) Insights into service operations management: A research agenda. Production Oper. Management 12(2):145-164.

Roth AV, Julian J, Malhotra MK (1995) Assessing customer value for engineering: Narcissistic practices and parameters from the next generation. Grover V, Kettinger W, eds. Business Process Change: Reengineering Concepts, Methods, and Technologies (Idea Group Publishing, Harrisburg, PA), 453-474.

Shockley J, Plummer LA, Roth AV, Fredendall LD (2015) Strategic design responsiveness: An empirical analysis of US retail store networks. Production Oper. Management. 24(3):451-468.

Stewart R, Mohamed S (2002) IT/IS projects selection using multi-criteria utility theory. Logist. Inform. Management 15(4):254-270.

Stigler GJ (1950) The development of utility theory I. J. Political Econom. 58(4):307-327.

Swaddling DC, Miller C (2002) Don’t measure customer satisfaction. Quality Progress 35(5):62-67. 
Verma R, Plaschka G (2003) The art and science of customer-choice modeling: Reflections, advances, and managerial implications. Cornell Hotel Restaurant Admin. Quart. 44(56):156-165.

Verma R, Young ST (2000) Configurations of low-contact services. J. Oper. Management 18(6):643-661.

Verma R, Louviere JJ, Burke P (2006) Using a market-utility-based approach to designing public services: A case illustration from United States Forest Service. J. Oper. Management 24(4):407-416.

Verma R, Plaschka G, Louviere JJ (2002) Understanding customer choices: A key to successful service management. Cornell Hotel Restaurant Admin. Quart. 43(4):15-24.

Verma R, Thompson GM, Louviere JJ (1999) Configuring service operations in accordance with customer needs and preferences. J. Service Res. 1(3):262-274.

Vermeulen B, Goos P, Vandebroek M (2010) Obtaining more information from conjoint experiments by best-worst choices. Comput. Statist. Data Anal. 54(6):1426-1433.

Victorino L, Verma R, Plaschka G, Dev C (2005) Service innovation and customer choices in the hospitality industry. Managing Service Quality. 15(6):555-576.

Voss C, Roth AV, Chase RB (2008) Experience, service operations strategy, and services as destinations: Foundations and exploratory investigation. Production Oper. Management 17(3):247-266.

Walker RH, Craig-Lees M, Hecker R, Francis H (2002) Technology-enabled service delivery: An investigation of reasons affecting customer adoption and rejection. Internat. J. Service Indust. Management 13(1):91-106. 
Wallenius J, Dyer JS, Fishburn PC, Steuer RE, Zionts S, Deb K (2008) Multiple criteria decision making, multiattribute utility theory: Recent accomplishments and what lies ahead. Management Sci. 54(7):1336-1349.

Wang C, Harris J, Patterson PG (2012) Customer choice of self-service technology: The roles of situational influences and past experience. J. Service Management 23(1):54-78.

West DM (2012) How mobile devices are transforming healthcare. Issues Tech. Innovation 18:1-14.

Woodruff RB (1997) Customer value: The next source for competitive advantage. J. Acad. Marketing Sci. 25(2):139-153.

Worstall T (2013) After only a month the Facebook phone is down to 99 cents. Forbes (May 9), http://www.forbes.com/sites/timworstall/2013/05/09/after-only-a-month-the-facebookphone-is-down-to-99-cents/.

Xue M, Hitt LM, Harker PT (2007) Customer efficiency, channel usage, and firm performance in retail banking. Manufacturing Service Oper. Management 9(4):535-558.

Zeithaml VA (1988) Consumer perceptions of price, quality, and value: A means-end model and synthesis of evidence. J. Marketing 52(3):2-22.

Zeithaml VA (2002) Service excellence in electronic channels. Managing Service Quality 12(3):135-139. 
Table 1. Descriptive Statistics.

\begin{tabular}{lc} 
Characteristics & Total sample (1093) \\
\hline Aqe qroup & \\
20-24 years (1) & 0.4 \\
25-34 years (2) & 3.4 \\
35-44 years (3) & 6.8 \\
45-54 years (4) & 20.5 \\
55-64 years (5) & 35.3 \\
65+ years (6) & 33.6 \\
Gender & \\
Male (0) & 40.2 \\
Female (1) & 59.8 \\
Income group & \\
Under \$50k (1) & 15.2 \\
\$50k-\$99.9k (2) & 35.7 \\
\$100k-\$149.9k (3) & 28.5 \\
\$150k-\$200k (4) & 10.3 \\
More than \$200k (5) & 10.3 \\
Education group & \\
High school (1) & 7.8 \\
College (2) & 60.4 \\
Post-graduate (3) & 31.8 \\
Marital status & \\
Single (0) & 19.3 \\
Married or living with partner (1) & 80.7
\end{tabular}

Note. The numbers in parentheses indicate coding used for the analysis. 
Table 2. Restaurant Technologies Component Score Coefficient.

\begin{tabular}{|c|c|c|c|c|c|c|}
\hline \multirow[b]{2}{*}{$\begin{array}{l}\text { Service innovation } \\
\text { category }\end{array}$} & \multirow[b]{2}{*}{ Technology } & \multicolumn{5}{|c|}{ Component } \\
\hline & & 1 & 2 & 3 & 4 & 5 \\
\hline \multirow[t]{3}{*}{ Tablet-based } & $\begin{array}{l}\text { Tablet computer-based ordering by } \\
\text { customer }\end{array}$ & 0.448 & 0.001 & $\begin{array}{l}-0.02 \\
0\end{array}$ & $\begin{array}{l}-0.06 \\
2\end{array}$ & $\begin{array}{l}-0.01 \\
8\end{array}$ \\
\hline & $\begin{array}{l}\text { Tablet computer-based order-taking } \\
\text { by wait staff }\end{array}$ & 0.454 & $\begin{array}{l}-0.08 \\
3\end{array}$ & $\begin{array}{l}-0.12 \\
4\end{array}$ & 0.106 & $\begin{array}{l}-0.04 \\
8\end{array}$ \\
\hline & $\begin{array}{l}\text { Tablet computer-based satisfaction } \\
\text { survey }\end{array}$ & 0.455 & 0.027 & 0.038 & $\begin{array}{l}-0.17 \\
2\end{array}$ & $\begin{array}{l}-0.10 \\
5\end{array}$ \\
\hline \multirow[t]{2}{*}{ Mobile-based } & Mobile website & 0.027 & 0.503 & $\begin{array}{l}-0.05 \\
5\end{array}$ & 0.004 & $\begin{array}{l}-0.12 \\
4\end{array}$ \\
\hline & Mobile apps & $\begin{array}{l}-0.01 \\
9\end{array}$ & 0.498 & $\begin{array}{l}-0.07 \\
4\end{array}$ & $\begin{array}{l}-0.03 \\
2\end{array}$ & 0.071 \\
\hline \multirow[t]{2}{*}{ Kiosk-based } & Kiosk-based payment & $\begin{array}{l}-0.06 \\
9\end{array}$ & $\begin{array}{l}-0.09 \\
2\end{array}$ & 0.547 & 0.018 & 0.044 \\
\hline & Kiosk-based food ordering & $\begin{array}{l}-0.04 \\
3\end{array}$ & $\begin{array}{l}-0.05 \\
9\end{array}$ & 0.528 & 0.026 & $\begin{array}{l}-0.01 \\
4\end{array}$ \\
\hline \multirow[t]{3}{*}{ Queue management } & Online table reservations & $\begin{array}{l}-0.03 \\
7\end{array}$ & $\begin{array}{l}-0.14 \\
2\end{array}$ & $\begin{array}{l}-0.10 \\
1\end{array}$ & 0.510 & 0.169 \\
\hline & Pagers for wait-time management & $\begin{array}{l}-0.10 \\
4\end{array}$ & $\begin{array}{l}-0.03 \\
6\end{array}$ & $\begin{array}{l}-0.00 \\
1\end{array}$ & 0.459 & $\begin{array}{l}-0.10 \\
0\end{array}$ \\
\hline & Internet-based ordering & $\begin{array}{l}-0.09 \\
5\end{array}$ & 0.148 & 0.029 & 0.398 & $\begin{array}{l}-0.13 \\
0\end{array}$ \\
\hline \multirow[t]{3}{*}{ Payment } & Payment via smart credit card & $\begin{array}{l}-0.09 \\
9\end{array}$ & 0.015 & 0.059 & $\begin{array}{l}-0.11 \\
9\end{array}$ & 0.592 \\
\hline & Payment via smart phone & $\begin{array}{l}-0.16 \\
2\end{array}$ & 0.210 & 0.037 & $\begin{array}{l}-0.01 \\
1\end{array}$ & 0.386 \\
\hline & $\begin{array}{l}\text { Table-side payment by handheld } \\
\text { device }\end{array}$ & 0.172 & $\begin{array}{l}-0.23 \\
2\end{array}$ & $\begin{array}{l}-0.11 \\
2\end{array}$ & 0.055 & 0.446 \\
\hline
\end{tabular}

Notes. We used cutoff value of 0.35 for variables that loaded on any factors. Therefore, two variables were deleted and not considered in any subsequent analyses. Numbers in bold indicate coefficient greater than 0.35 . 
Table 3. Cluster Results: Strategic Groups by Technology Usage

\begin{tabular}{|c|c|c|c|c|c|}
\hline $\begin{array}{l}\text { Technology } \\
\text { usage variables }\end{array}$ & $\begin{array}{l}\text { Physical } \\
\text { device users } \\
(n=106)\end{array}$ & $\begin{array}{l}\text { Virtual } \\
\text { device users } \\
(n=173)\end{array}$ & $\begin{array}{l}\text { Functional } \\
\text { device users } \\
(n=244)\end{array}$ & $\begin{array}{l}\text { Low } \\
\text { users } \\
(n=570) \\
\end{array}$ & $\begin{array}{c}F \text {-value } \\
(p= \\
\text { probability })\end{array}$ \\
\hline \multicolumn{6}{|l|}{ Usage-Tablet } \\
\hline Cluster mean & $57.93(3,4)$ & $55.78(3,4)$ & $50.98(1,2,4)$ & $45.57(1,2,3)$ & $F=117.122$ \\
\hline Rank & 2 & 2 & 3 & 2 & $(p=0.000)$ \\
\hline Std. dev. & 11.89 & 10.81 & 9.48 & 5.41 & \\
\hline \multicolumn{6}{|l|}{ Usage-Mobile } \\
\hline Cluster mean & $51.63(2,3,4)$ & $65.21(1,3,4)$ & $45.81(1,2)$ & $45.43(1,2)$ & $F=485.498$ \\
\hline Rank & 3 & 1 & 5 & 3 & $(p=0.000)$ \\
\hline Std. dev. & 9.81 & 6.85 & 5.39 & 5.39 & \\
\hline \multicolumn{6}{|l|}{ Usage-Kiosk } \\
\hline Cluster mean & $\mathbf{7 1 . 8 7}(2,3,4)$ & $47.86(1,3,4)$ & $46.01(1,2)$ & $46.56(2,3)$ & $F=799.730$ \\
\hline Rank & 1 & 5 & 4 & 1 & $(p=0.000)$ \\
\hline Std. dev. & 8.00 & 6.07 & 3.56 & 4.52 & \\
\hline \multicolumn{6}{|l|}{ Usage-Payment } \\
\hline Cluster mean & $51.40(3,4)$ & $52.09(3,4)$ & $\mathbf{5 9 . 4 1}(1,2,4)$ & $45.41(1,2,3)$ & $F=193.616$ \\
\hline Rank & 5 & 4 & 1 & 4 & $(p=0.000)$ \\
\hline Std. dev. & 10.00 & 10.96 & 7.37 & 5.99 & \\
\hline \multicolumn{6}{|l|}{ Usage-Queue } \\
\hline Cluster mean & $51.49(2,3,4)$ & $54.48(1,4)$ & $56.11(1,4)$ & $44.77(1,2,3)$ & $F=118.528$ \\
\hline Rank & 4 & 3 & 2 & 5 & $(p=0.000)$ \\
\hline Std. dev. & 9.96 & 7.28 & 5.26 & 10.25 & \\
\hline
\end{tabular}

Notes. The numbers in parentheses indicate the group numbers from which this group was significantly different at the 0.05 level as indicated by the Tukey pairwise comparison procedure. Numbers in bold indicate the highest group centroid for that measure. The observed F-statistics were derived from one-way ANOVAs and the p-values are associated with the observed F statistics. 
Table 4. Cluster Results: Strategic Groups by Technology Utility

\begin{tabular}{|c|c|c|c|c|c|}
\hline Variables & $\begin{array}{l}\text { Onsite control }(n= \\
\text { 256) }\end{array}$ & $\begin{array}{l}\text { Total process control } \\
(n=265)\end{array}$ & $\begin{array}{c}\text { Time control } \\
(n=270)\end{array}$ & $\begin{array}{l}\text { Tangible technology } \\
(n=302)\end{array}$ & $\begin{array}{c}F \text {-value } \\
(p=\text { probability })\end{array}$ \\
\hline \multicolumn{6}{|l|}{ Utility-Tablet } \\
\hline Cluster mean & $55.64(2,3)$ & $51.84(1,3,4)$ & $40.12(1,2,4)$ & $\mathbf{5 5 . 6 7}(2,3)$ & $F=261.198$ \\
\hline Rank & 1 & 3 & 5 & 2 & $(p=0.000)$ \\
\hline Std. dev. & 9.08 & 7.55 & 6.57 & 6.77 & \\
\hline \multicolumn{6}{|l|}{ Utility-Mobile } \\
\hline Cluster mean & $42.02(2,3,4)$ & $55.38(1,4)$ & $55.90(1,4)$ & $45.41(1,2,3)$ & $F=190.339$ \\
\hline Rank & 4 & 2 & 2 & 5 & $(p=0.000)$ \\
\hline Std. dev. & 8.72 & 6.98 & 8.30 & 3.06 & \\
\hline \multicolumn{6}{|l|}{ Utility-Kiosk } \\
\hline Cluster mean & $\mathbf{5 5 . 5 1}(2,3)$ & $38.56(1,3,4)$ & $49.29(1,2,4)$ & $54.18(2,3)$ & $F=304.428$ \\
\hline Rank & 2 & 5 & 4 & 3 & $(p=0.000)$ \\
\hline Std. dev. & 7.08 & 6.74 & 7.88 & 7.12 & \\
\hline \multicolumn{6}{|l|}{ Utility-Payment } \\
\hline Cluster mean & $54.10(2,3,4)$ & $\mathbf{5 6 . 8 6}(1,3,4)$ & $50.51(1,2,4)$ & $39.20(1,2,3)$ & $F=337.229$ \\
\hline $\begin{array}{c}\text { Rank } \\
\text { Std. dev. } \\
\text { Utility-Queue }\end{array}$ & $\begin{array}{c}3 \\
6.39\end{array}$ & $\begin{array}{c}1 \\
7.52\end{array}$ & $\begin{array}{c}3 \\
8.09\end{array}$ & $\begin{array}{c}5 \\
6.58\end{array}$ & $(p=0.000)$ \\
\hline Cluster mean & $41.12(2,3,4)$ & $46.16(1,3,4)$ & $56.67(1,2)$ & $55.82(1,2)$ & $F=272.155$ \\
\hline Rank & 5 & 4 & 1 & 1 & $(p=0.000)$ \\
\hline Std. dev. & 7.71 & 8.08 & 7.31 & 7.05 & \\
\hline
\end{tabular}

Notes. The numbers in parentheses indicate the group numbers from which this group was significantly different at the 0.05 level as indicated by the Tukey pairwise comparison procedure. Numbers in bold indicate the highest group centroid for that measure. The observed F -statistics were derived from one-way ANOVAs and the p-values are associated with the observed F -statistics. 
Table 5. Results of Canonical Discriminant Analysis (Technology Usage Groups)

\begin{tabular}{|c|c|c|c|c|c|c|}
\hline Canonical correlati & n function & Eigenvalue or root & $R_{C}$ & \multicolumn{2}{|c|}{ Squared canonical correlation } & $p$-value \\
\hline 1 & & 2.55 & 0.84 & \multicolumn{2}{|c|}{0.72} & $P<0.001$ \\
\hline 2 & & 1.52 & 0.78 & \multicolumn{2}{|c|}{0.60} & $P<0.001$ \\
\hline 3 & & 0.93 & 0.69 & \multicolumn{2}{|c|}{0.48} & $P<0.001$ \\
\hline \multicolumn{3}{|l|}{ Canonical loadings } & & \multicolumn{3}{|c|}{ Canonical coefficients } \\
\hline Variables & Function 1 & Function 2 & Function 3 & Function 1 & Function 2 & Function 3 \\
\hline Usage-Tablet & 0.47 & 0.35 & 0.14 & 0.44 & 0.27 & 0.06 \\
\hline Usage-Mobile & 0.39 & 0.81 & -0.38 & 0.33 & 1.21 & -0.83 \\
\hline Usage-Kiosk & 0.94 & -0.31 & -0.02 & 1.61 & -0.77 & 0.00 \\
\hline Usage-Payment & 0.15 & 0.36 & 0.73 & 0.02 & 0.32 & 1.03 \\
\hline Usage-Queue & 0.21 & 0.43 & 0.47 & 0.17 & 0.37 & 0.68 \\
\hline
\end{tabular}

Notes. Numbers in bold indicate high loadings (weights) in canonical functions $\pm|0040|$. The Wilk’s lambda $=0.06(\mathrm{~F}$ value $=360.28, \mathrm{df}=15, p<000001)$ indicates a significant overall multivariate relationship for five technology usage taxons. The three canonical correlations $\left(\mathrm{R}_{\mathrm{c} 1}\right.$ $\mathrm{D} 0084, \mathrm{R}_{\mathrm{c} 2} \mathrm{D}$ 0078, and $\mathrm{R}_{\mathrm{c} 3} \mathrm{D}$ 0069) for technology usage are statistically significant ( $p$ $<000001)$. 
Table 6. Results of Canonical Discriminant Analysis (Technology Utility Groups)

\begin{tabular}{|c|c|c|c|c|c|c|}
\hline \multicolumn{2}{|l|}{$\begin{array}{l}\text { Canonical } \\
\text { correlation function }\end{array}$} & $\begin{array}{c}\text { Eigenvalue or } \\
\text { root }\end{array}$ & $R_{C}$ & \multicolumn{2}{|c|}{$\begin{array}{c}\text { Squared canonical } \\
\text { correlation }\end{array}$} & $p$-value \\
\hline \multicolumn{2}{|l|}{1} & 1.90 & 0.81 & \multicolumn{2}{|c|}{0.65} & $P<0.001$ \\
\hline 2 & & 1.38 & 0.76 & \multicolumn{2}{|c|}{0.58} & $P<0.001$ \\
\hline 3 & & 0.32 & 0.49 & \multicolumn{2}{|c|}{0.24} & $P<0.001$ \\
\hline \multicolumn{4}{|l|}{ Canonical loadings } & \multicolumn{3}{|c|}{ Canonical coefficients } \\
\hline Variables & Function 1 & Function 2 & Function 3 & Function 1 & Function 2 & Function 3 \\
\hline Utility-Tablet & 0.34 & 0.67 & -0.58 & 0.24 & 0.66 & -0.48 \\
\hline Utility-Mobile & -0.55 & -0.49 & -0.15 & -0.57 & -0.55 & 0.02 \\
\hline Utility-Kiosk & 0.74 & 0.09 & 0.61 & 0.82 & -0.10 & 0.91 \\
\hline Utility-Payment & -0.74 & 0.35 & 0.46 & -0.84 & 0.28 & 0.67 \\
\hline Utility-Queue & 0.26 & $-\mathbf{0 . 8 0}$ & -0.25 & 0.26 & -0.94 & -0.02 \\
\hline
\end{tabular}

Notes. Numbers in bold indicate high loadings (weights) in canonical functions $\pm|0040|$. The Wilk’s lambda $=0.11(\mathrm{~F}$ value $=245.25, \mathrm{df}=15, p<000001)$ indicates a significant overall multivariate relationship for five technology utility taxons. The three canonical correlations $\left(\mathrm{R}_{\mathrm{c} 1}\right.$ $=0081, \mathrm{R}_{\mathrm{c} 2}=0076$, and $\left.\mathrm{R}_{\mathrm{c} 3}=0049\right)$ for technology utility are statistically significant $(p$ $<000001)$. 
Table 7. Number of Observations and Percentage Cross Validated: Strategic Groups for Technology Usage

\begin{tabular}{|c|c|c|c|c|c|}
\hline & 1 & 2 & 3 & 4 & \\
\hline From/To & $\begin{array}{c}\text { Physical device } \\
\text { users }\end{array}$ & $\begin{array}{c}\text { Virtual device } \\
\text { users }\end{array}$ & $\begin{array}{c}\text { Functional device } \\
\text { users }\end{array}$ & Low users & Total \\
\hline 1 & 104 (98.11\%) & 2 (1.89\%) & $0(0.00 \%)$ & $0(0.00 \%)$ & 106 (100\%) \\
\hline 2 & $2(1.16 \%)$ & 166 (95.95\%) & 5 (2.89\%) & $0(0.00 \%)$ & 173 (100\%) \\
\hline 3 & $2(0.82 \%)$ & $0(0.00 \%)$ & 235 (96.31\%) & 7 (2.87\%) & 244 (100\%) \\
\hline 4 & 18 (3.16\%) & 7 (1.23\%) & $2(0.35 \%)$ & 543 (95.26\%) & $570(100 \%)$ \\
\hline $\begin{array}{l}\text { Error rates } \\
\text { from cross- }\end{array}$ & 0.0189 & 0.0405 & 0.0369 & 0.0474 & 0.0359 \\
\hline
\end{tabular}


Table 8. Number of Observations and Percentage Cross Validated: Strategic Groups for Technology Utility

\begin{tabular}{lccccc}
\hline & 1 & 2 & 3 & 4 & \\
\cline { 2 - 4 } From/To & Onsite control & $\begin{array}{c}\text { Total } \\
\text { process }\end{array}$ & Time control & $\begin{array}{c}\text { Tangible } \\
\text { technolog }\end{array}$ & \multirow{2}{*}{ Total } \\
\hline 1 & $243(94.92 \%)$ & $5(1.95 \%)$ & $0(0.00 \%)$ & $8(3.13 \%)$ & $256(100 \%)$ \\
2 & $4(1.51 \%)$ & $257(96.98 \%)$ & $4(1.51 \%)$ & $0(0.00 \%)$ & $265(100 \%)$ \\
3 & $1(0.37 \%)$ & $5(1.85 \%)$ & $258(95.56 \%)$ & $6(2.22 \%)$ & $270(100 \%)$ \\
4 & $9(2.98 \%)$ & $2(0.66 \%)$ & $5(1.66 \%)$ & $286(94.70 \%)$ & $302(100 \%)$ \\
Error rates & 0.0508 & 0.0302 & 0.0444 & 0.0530 & 0.0446 \\
from: Cross- & & & & & \\
\hline
\end{tabular}


Table 9. Technology Usage vs. Utility Groups

\begin{tabular}{lccccc}
\hline & \multicolumn{5}{c}{ Technology utility strategic groups } \\
\cline { 2 - 5 } Technology & Tangible & & \multicolumn{3}{c}{ Total process } \\
usage strategic groups & $\begin{array}{c}\text { control } \\
\text { technology }\end{array}$ & Onsite control & Time control & Total \\
\hline Physical device & $31^{\mathrm{a}}$ & 35 & 22 & 18 & 106 \\
users & $29.3^{\mathrm{b}}$ & 24.8 & 26.2 & 25.7 & 106.0 \\
& $(10.3 \%)^{\mathrm{C}}$ & $(13.7 \%)$ & $(8.1 \%)$ & $(6.8 \%)$ & $(9.7 \%)$ \\
Virtual device & $(2.8 \%)^{\mathrm{d}}$ & $(3.2 \%)$ & $(2.0 \%)$ & $(1.6 \%)$ & $(9.7 \%)$ \\
users & 31 & 20 & 60 & 62 & 173 \\
& 47.8 & 40.5 & 42.7 & 41.9 & 173.0 \\
Functional device & $(10.3 \%)$ & $(7.8 \%)$ & $(22.2 \%)$ & $(23.4 \%)$ & $(15.8 \%)$ \\
users & $(2.8 \%)$ & $(1.8 \%)$ & $(5.5 \%)$ & $(5.7 \%)$ & $(15.8 \%)$ \\
& 56 & 49 & 66 & 73 & 244 \\
Low users & 67.4 & 57.1 & 60.3 & 59.2 & 244.0 \\
& $(18.5 \%)$ & $(19.1 \%)$ & $(24.4 \%)$ & $(27.5 \%)$ & $(22.3 \%)$ \\
& $(5.1 \%)$ & $(4.5 \%)$ & $(6.0 \%)$ & $(6.7 \%)$ & $(22.3 \%)$ \\
& 184 & 152 & 122 & 112 & 570 \\
Total & 157.5 & 133.5 & 140.8 & 138.2 & 570.0 \\
& $(60.9 \%)$ & $(59.4 \%)$ & $(45.2 \%)$ & $(42.3 \%)$ & $(52.2 \%)$ \\
& $(16.8 \%)$ & $(13.9 \%)$ & $(11.2 \%)$ & $(10.2 \%)$ & $(52.2 \%)$ \\
& 302 & 256 & 270 & 265 & 1,093 \\
& 302.0 & 256.0 & 270.0 & 265.0 & $1,093.0$ \\
& $(100 \%)$ & $(100 \%)$ & $(100 \%)$ & $(100 \%)$ & $(100 \%)$ \\
& $(27.6 \%)$ & $(23.4 \%)$ & $(24.7 \%)$ & $(24.2 \%)$ & $(100 \%)$ \\
\hline
\end{tabular}

Notes. Chi-square test was performed and found that cluster membership of technology utility is associated with that of technology usage ( $\chi^{2}=61.485, d f=9, p=0.000$ )

${ }^{\mathrm{a} C o u n t .}$

${ }^{\mathrm{b}}$ Expected count.

$\mathrm{c} \%$ within cluster $=$ frequency/column total.

$\mathrm{d} \%$ of total $=$ frequency/total. 
Table 10. Other Variables Associated with Strategic Groups on Technology Usage

\begin{tabular}{|c|c|c|c|c|c|}
\hline Other variables & $\begin{array}{c}\text { Physical } \\
\text { device users } \\
(n=106)\end{array}$ & $\begin{array}{c}\text { Virtual } \\
\text { device users } \\
(n=173)\end{array}$ & $\begin{array}{l}\text { Functional } \\
\text { device users } \\
(n=244)\end{array}$ & $\begin{array}{c}\text { Low } \\
\text { users } \\
(n=570)\end{array}$ & $\begin{array}{c}F \text {-value } \\
(p=\text { probability })\end{array}$ \\
\hline \multicolumn{6}{|c|}{ How often_Kiosk/Cafe } \\
\hline Cluster mean* & $5.59(4)$ & $5.13(4)$ & $5.07(4)$ & $4.11(1,2,3)$ & $F=17.490$ \\
\hline Std. dev. & 2.40 & 2.64 & 2.67 & 2.50 & $(p=0.000)$ \\
\hline \multicolumn{6}{|l|}{ Fast Food } \\
\hline Cluster mean* & $6.42(3)$ & $6.29(3)$ & $5.12(1,2,4)$ & $5.88(3)$ & $F=14.104$ \\
\hline Std. dev. & 2.00 & 2.07 & 2.32 & 2.16 & $(p=0.000)$ \\
\hline \multicolumn{6}{|l|}{ Fast Casual } \\
\hline Cluster mean* & $6.42(3,4)$ & $6.43(3,4)$ & $5.44(1,2,4)$ & $5.84(1,2,3)$ & $F=10.706$ \\
\hline Std. dev. & 2.05 & 1.85 & 2.08 & 2.06 & $(p=0.000)$ \\
\hline \multicolumn{6}{|l|}{ Casual Dining } \\
\hline Cluster mean* & 6.90 & $7.20(3,4)$ & $6.74(2)$ & $6.83(2)$ & $F=4.413$ \\
\hline Std. dev. & 1.41 & 1.29 & 1.38 & 1.34 & $(p=0.004)$ \\
\hline \multicolumn{6}{|l|}{ Upscale Casual } \\
\hline Cluster mean* & $5.67(2)$ & $6.20(1,4)$ & $6.08(4)$ & $5.44(2,3)$ & $F=14.309$ \\
\hline Std. dev. & 1.91 & 1.62 & 1.40 & 1.69 & $(p=0.000)$ \\
\hline \multicolumn{6}{|l|}{ Fine Dining } \\
\hline Cluster mean* & 4.57 & $5.05(4)$ & 4.99 (4) & $4.20(2,3)$ & $F=17.408$ \\
\hline Std. dev. & 1.94 & 1.71 & 1.54 & 1.83 & $(p=0.000)$ \\
\hline \multicolumn{6}{|l|}{ TRI } \\
\hline Cluster mean & $3.57(2,4)$ & $5.76(1,3,4)$ & $3.10(2,4)$ & $1.26(1,2,3)$ & $F=27.593$ \\
\hline Std. dev. & 6.18 & 5.42 & 5.29 & 6.22 & $(p=0.000)$ \\
\hline \multicolumn{6}{|l|}{ Secondary Review } \\
\hline Cluster mean** & 2.79 & $2.98(4)$ & $2.95(4)$ & $2.63(2,3)$ & $F=17.497$ \\
\hline Std. dev. & 0.77 & 0.75 & 0.66 & 0.75 & $(p=0.000)$ \\
\hline \multicolumn{6}{|l|}{$\begin{array}{l}\text { Personalized } \\
\text { Information }\end{array}$} \\
\hline Cluster mean ${ }^{* *}$ & $2.06(3,4)$ & $2.19(3,4)$ & $1.76(1,2)$ & $1.77(1,2)$ & $F=22.372$ \\
\hline Std. dev. & 0.68 & 0.69 & 0.63 & 0.68 & $(p=0.000)$ \\
\hline \multicolumn{6}{|l|}{ Word of Mouth } \\
\hline Cluster mean** & 3.86 & 3.97 & 3.91 & 3.93 & $F=1.449$ \\
\hline Std. dev. & 0.48 & 0.44 & 0.48 & 0.46 & $(p=0.227)$ \\
\hline \multicolumn{6}{|l|}{ Gender*** } \\
\hline Cluster mean & 0.55 & 0.62 & 0.59 & 0.60 & $F=.429$ \\
\hline
\end{tabular}


$\begin{array}{llllll}\text { Std. dev. } & 0.50 & 0.49 & 0.49 & 0.49 & (p=0.733)\end{array}$

\begin{tabular}{|c|c|c|c|c|c|}
\hline \multicolumn{6}{|l|}{ Age } \\
\hline Cluster mean & $5.54(3,4)$ & $5.43(3,4)$ & $\mathbf{6 . 0 5}(1,2)$ & $6.00(1,2)$ & $F=18.681$ \\
\hline Std. dev. & 1.27 & 1.24 & 0.98 & 0.980 & $(p=0.000)$ \\
\hline \multicolumn{6}{|l|}{ Education $^{* * *}$} \\
\hline Cluster mean & 2.28 & 2.24 & $2.34(4)$ & 2.19 (3) & $F=4.071$ \\
\hline Std. dev. & 0.60 & 0.55 & 0.56 & 0.59 & $(p=0.007)$ \\
\hline \multicolumn{6}{|l|}{ Income $e^{* * *}$} \\
\hline Cluster mean & 2.69 & $3.00(4)$ & $2.95(4)$ & $2.41(2,3)$ & $F=20.175$ \\
\hline Std. dev. & 1.29 & 1.27 & 1.20 & 1.03 & $(p=0.000)$ \\
\hline \multicolumn{6}{|l|}{ Marital Status*** } \\
\hline Cluster mean & 0.76 & 0.81 & $0.87(4)$ & $0.79(3)$ & $F=2.719$ \\
\hline Std. dev. & 0.43 & 0.39 & 0.34 & 0.41 & $(p=0.043)$ \\
\hline
\end{tabular}

Notes. Numbers in parentheses indicate the group numbers from which this group was significantly different at the 0.05 level as indicated by the Tukey pairwise comparison procedure. Numbers in bold indicate the highest group centroid for that measure. The observed $F$-statistics were derived from one-way ANOVAs and the $p$-values are associated with each of the observed $F$-statistics.

*Represents the average values measured on 10-point scales (interval scale 1-10).

**Represents the average values measured on five-point scales (interval scale 1-5). ***See Table 1 for demographic classifications. 
Table 11. Other Variables for Strategic Groups on Technology Utility.

\begin{tabular}{|c|c|c|c|c|c|}
\hline Other variables & $\begin{array}{c}\text { Onsite control } \\
(n=256)\end{array}$ & $\begin{array}{c}\text { Total process } \\
\text { control }(n=265)\end{array}$ & $\begin{array}{c}\text { Time control } \\
(n=270)\end{array}$ & $\begin{array}{c}\text { Tangible technology } \\
(n=302)\end{array}$ & $\begin{array}{c}F \text {-value } \\
(p=\text { probability })\end{array}$ \\
\hline \multicolumn{6}{|c|}{ How often_Kiosk/Cafe } \\
\hline Cluster mean* & 4.90 & 4.51 & 4.70 & 4.45 & $F=1.638$ \\
\hline Std. dev. & 2.57 & 2.64 & 2.66 & 2.55 & $(p=0.179)$ \\
\hline \multicolumn{6}{|l|}{ Fast Food } \\
\hline Cluster mean* & $6.09(2)$ & $5.59(1)$ & 5.62 & 6.01 & $F=3.708$ \\
\hline Std. dev. & 2.10 & 2.38 & 2.17 & 2.14 & $(p=0.011)$ \\
\hline \multicolumn{6}{|l|}{ Fast Casual } \\
\hline Cluster mean* & 6.03 & 5.77 & 5.77 & 6.03 & $F=1.461$ \\
\hline Std. dev. & 2.12 & 2.18 & 2.08 & 1.87 & $(p=0.223)$ \\
\hline \multicolumn{6}{|l|}{ Casual Dining } \\
\hline Cluster mean* & 6.73 & 6.95 & 6.90 & 6.91 & $F=1.341$ \\
\hline Std. dev. & 1.36 & 1.45 & 1.46 & 1.16 & $(p=0.260)$ \\
\hline
\end{tabular}

How often_Upscale Casual

Cluster mean*

Std. dev.

Fine Dining

Cluster mean*

Std. dev.

TRI

Cluster mean

Std. dev.

Secondary Review

Cluster mean ${ }^{* *}$

Std. dev.

Personalized

Information

Cluster mean**

Std. dev.

Word of Mouth

Cluster mean ${ }^{* *}$

Std. dev.

Gender***

Cluster mean

Std. dev.

Age***

Cluster mean

Std. dev.

Education***

Cluster mean

Std. dev.
$5.27(2,3,4)$

1.79

$4.18(2,3)$

1.83

$2.01(2)$

6.09

$3.87(1,4)$

$2.59(2,3,4)$

0.81

1.84

0.74

3.88 (4)

0.46

0.59

0.49

5.90

1.10

2.22

0.59
5.71

2.90 (1)

0.73

$6.02(1,4) \quad 5.96(1)$

1.64

4.72 (1)

1.76

3.08 (4)

6.18

2.82 (1)

0.73

$1.99(3,4)$

0.69

1.83 (2)

0.64

3.90

0.45

0.63

0.48

$5.72(4)$

1.11

2.22

0.59
2.28

0.57
$5.64(1,2)$

1.56

4.37 (2)

1.76

$1.58(2,3)$

6.34

2.78 (1)

0.69

1.81 (2)

0.67

3.99 (1)

0.46

0.60

0.49

$5.98(2)$

1.03

2.25

0.59
$F=11.471$

$(p=0.000)$

Income $e^{* * *}$

$F=9.443$

$(p=0.000)$

$F=7.996$

$(p=0.000)$

$F=8.212$

$(p=0.000)$

$F=3.904$

$(p=0.009)$

$F=3.018$

$(p=0.029)$

$F=0.767$

$(p=0.513)$

$F=2.751$

$(p=0.042)$

$F=0.675$

$(p=0.568)$ 


\begin{tabular}{lccccc} 
Cluster mean & $2.41(2,3)$ & $\mathbf{2 . 8 7}(1,4)$ & $2.73(1)$ & $2.59(2)$ & $F=7.828$ \\
$\begin{array}{l}\text { Std. dev. } \\
\text { Marital Status*** }\end{array}$ & 1.08 & 1.23 & 1.21 & 1.10 & $(p=0.000)$ \\
$\quad$ Cluster mean & & & & & \\
Std. dev. & 0.77 & 0.82 & 0.82 & 0.82 & $F=1.168$ \\
& 0.43 & 0.39 & 0.39 & 0.38 & $(p=0.321)$ \\
\hline
\end{tabular}

Notes. Numbers in parentheses indicate the group numbers from which this group was significantly different at the 0.05 level as indicated by the Tukey pairwise comparison procedure. Numbers in bold indicate the highest group centroid for that measure. The observed $F$-statistics were derived from one-way ANOVAs and the p-values are associated with each of the observed $F$-statistics.

*Represents the average values measured on 10-point scales (interval scale 1-10).

**Represents the average values measured on five-point scales (interval scale 1-5).

***See Table 1 for demographic classifications. 
Comell University

School of Hotel Administration

The Center for Hospitality Research

MD_3 3

Considering only the following 7 restaurant technologies, please indicate the one that is Least Attractive and the one that is Most Attractive to you.

\begin{tabular}{|c|c|c|}
\hline $\begin{array}{c}\text { Least } \\
\text { Attractive }\end{array}$ & $\begin{array}{c}\text { Most } \\
\text { Attractive }\end{array}$ \\
\hline$\bigcirc$ & Pagers for wait-time management & \\
\hline$\bigcirc$ & Payment via smart-phone & \\
\hline$\bigcirc$ & Tablet computer-based order-taking by wait-staff & $\bigcirc$ \\
\hline$\bigcirc$ & Tablet computer-based ordering by customer & $\bigcirc$ \\
\hline$\bigcirc$ & Mobile Apps & $\bigcirc$ \\
\hline$\bigcirc$ & Internet-based ordering & $\bigcirc$ \\
\hline
\end{tabular}

mdc 3

Screpn 3 of 6

Figure 1. A Sample Best-Worst Exercise Screenshot 